\title{
Advanced Thermal Sensors for Precision AC Voltage Metrology
}

\author{
Thomas E. Lipe, Joseph R. Kinard, Donald B. Novotny, and June E. Sims \\ Quantum Electrical Metrology Division \\ National Institute of Standards and Technology \\ Gaithersburg, MD 20899-8171 USA \\ Email: thomas.lipe@nist.gov
}

\begin{abstract}
We describe a new generation of thermal sensors for the measurement of ac voltages at frequencies up to $100 \mathrm{MHz}$. Electronics grade fused silica has been selected as a substrate material because it is significantly more robust than the previous generation of crystalline quartz, yet retains excellent dielectric properties. We report the design and fabrication of the new sensors, including the method of forming thin membranes, and present results for two sensor designs. Our latest devices show a reduction in the RF-DC of more than an order of magnitude over traditional high-frequency thermal sensors. We anticipate that the new sensors will enable significant reductions in the uncertainties in the NIST calibration service for RF-DC thermal converters.
\end{abstract}

\section{INTRODUCTION}

The most accurate method of measuring ac voltage at frequencies from $10 \mathrm{~Hz}$ to $100 \mathrm{MHz}$ is by comparing the heating effects of an unknown ac signal to that of a known dc reference using thermal converters $[1,2]$. Traditional single junction thermal converters (SJTCs) consist of a thin heater wire suspended between posts, with a thermocouple placed at the midpoint of the heater. The thermocouple senses the heat generated as both ac and dc voltages are applied to the heater; by comparing the outputs of the thermocouple as each signal is applied, the unknown ac voltage can be determined in terms of the known dc reference. In a perfect thermal converter, the ac and dc signals would produce identical output emfs, leading to a zero ac-dc transfer difference.

Thermal converters of this type are subject to a variety of error sources, including Thomson and Joule effects, skin effect in the leads, and heat flow through the heater posts. In general, traditional vacuum bulb thermal converters have ac-dc transfer differences as small as a few microvolts-per-volt at a few volts up to about $20 \mathrm{kHz}$; at higher frequencies, skin effect and transmission line effects in the heater rapidly increase the acdc difference so that at $100 \mathrm{MHz}$, depending on the characteristics of the heater, the ac-dc difference can be as

Contribution of the United States Government. Not subject to copyright in the U.S. NIST is an agency of the U.S. Department of Commerce. Supported in part by CCG Project 546. large as $10 \%$.

Many of these error sources can be reduced by using multiple thermocouples in proximity to a longer heater, forming a multijunction thermal converter (MJTC) [3,4]. Owing to the greater number of thermocouples, the operating temperature of the MJTC can be less than that of a traditional thermal converter, reducing temperature-dependent errors such as Thomson and Joule effects to negligible levels. MJTCs on silicon substrates made using semiconductor fabrication techniques can achieve ac-dc differences of less than $1 \mu \mathrm{V} / \mathrm{V}$ from $10 \mathrm{~Hz}$ to about $100 \mathrm{kHz}$, and devices of this type are routinely used as primary standards for ac voltage metrology in national metrology institutes (NMIs) worldwide $[5,6]$.

Unfortunately, silicon has a large relative permittivity $\left(\varepsilon_{r} \approx\right.$ 11.8 ) resulting in capacitive coupling between the heater and thermocouples through the silicon membrane and obelisk at high frequencies [7]. The large ac-dc differences (up to $5 \%$ at $100 \mathrm{MHz}$ ) resulting from this coupling restricts the use of silicon-based MJTCs to frequencies less than $1 \mathrm{MHz}$. To obtain standards with improved performance at high frequencies, NIST and other National Metrology Institutes have developed MJTCs based on both crystalline quartz and fused silica substrates [8-10]. Both materials have significantly smaller relative permittivity than silicon $\left(\varepsilon_{r} \approx 3.8\right.$ for fused silica) that reduces the high-frequency errors. Since crystalline quartz proved too fragile to fabricate reliably, we have focused our work on electronics-grade fused silica.

\section{Design OF High-FreQuenCy MJTCS}

\section{A. Membrane}

Like silicon, fused silica conducts heat quite well. For the thermocouples to operate efficiently, the heat generated in the heater structure must flow only to the hot junctions of the thermocouples, while leaving the cold junctions unaffected. We achieve this isothermal region by removing material from the backside of the wafer, leaving a thin membrane. The 
membrane should be as thin as possible for maximum isothermality, but still robust enough to support the heater. In practice, membranes of about $10 \mu \mathrm{m}$ to $20 \mu \mathrm{m}$ in thickness provide a good balance between stiffness and isothermality.

\section{B. Heater}

The heater design presents the greatest design challenge. The ac-dc difference of a thermal converter at high frequencies is largely determined by skin effect in the heater and by capacitive effects in the entire structure. The skin effect results in a positive, generally linear error that is inversely dependent on the heater resistance. The capacitive errors include distributed coupling between the heater and thermocouples through the membrane, and coupling between the bonding pads of the heater, and generally make a negative square-law contribution. Simulations of our design indicate that these effects should cancel each other at a resistance of about $700 \Omega$.

In addition to the heater design, the temperature coefficient of resistance (TCR) of the heater material should be small in order to minimize the resistance change with changing voltage. We have chosen an excellent material used for year in precision resistors, $\mathrm{Ni}_{75} \mathrm{Cr}_{20} \mathrm{Al}_{2.5} \mathrm{Cu}_{2.5}$, which has a TCR of about $10 \mu \mathrm{V} / \mathrm{V} /{ }^{\circ} \mathrm{C}$. Although this material is readily sputtered, the resulting film is prone to crazing at deposition thicknesses greater than a few hundred nanometers. We therefore utilized two designs in order to fine-control the heater resistance. One design features a straight (coaxial) heater; the other a $\cap$ shaped (bifilar) heater. Owing to the size of the structure, the bifilar heater has a resistance of about 3.375 times that of the coaxial, making it relatively easy to produce a variety of heater resistances.

\section{Thermocouples}

Our thermocouples are $\mathrm{Cu}_{55} \mathrm{Ni}_{45}$ and $\mathrm{Ni}_{80} \mathrm{Cr}_{20}$ with a Seebeck coefficient for the pair of about $65 \mu \mathrm{V} / \mathrm{K}$. The $\mathrm{Ni}_{80} \mathrm{Cr}_{20}$ legs are formed as a continuous track with the $\mathrm{Cu}_{55} \mathrm{Ni}_{45}$ legs sputtered atop the underlying layer, a structure known as plated thermocouples. The thermocouple junctions are made at the interface between the $\mathrm{Ni}_{80} \mathrm{Cr}_{20}$ track and the $\mathrm{Cu}_{55} \mathrm{Ni}_{45}$ legs. Forming the thermocouples in this fashion eliminates possible open circuits if the two materials do not form good contacts at the interfaces, and improves the yield. The thermocouple metals are each about $380 \mathrm{~nm}$ thick, about $1015 \mu \mathrm{m}$ in length, and $20 \mu \mathrm{m}$ wide. With 104 thermocouples in total, this metal thickness yields an output resistance for the MJTC of about $20 \mathrm{k} \Omega$. While it is desirable to reduce the output resistance, thicker metallization often results in crazing of the films.

\section{FABRICATION}

We begin with an electronics-grade $76 \mathrm{~mm}$ diameter fused silica wafer, nominally $500 \mu \mathrm{m}$ thick. A gold etch mask $50 \mathrm{~nm}$ thick is applied to the backside. This backside mask provides a guide for the back-etching of the wafer and also allows the MJTC to be grounded through the alumina substrate if desired. Following the backside gold deposition, the wafer is sent to a commercial micro-bead blasting company where the silica inside the windows of the backside mask is removed to form membranes $10 \mu \mathrm{m}$ to $25 \mu \mathrm{m}$ thick.

The $\mathrm{Ni}_{75} \mathrm{Cr}_{20} \mathrm{Al}_{2.5} \mathrm{Cu}_{2.5}$ heater is applied using sputter deposition using the appropriate time to yield the desired metal thickness. The $\mathrm{Ni}_{75} \mathrm{Cr}_{20} \mathrm{Al}_{2.5} \mathrm{Cu}_{2.5}$ is removed using wet chemical etching to leave the heater and streets used for dicing the wafer. The thermocouples are formed by sputter deposition and liftoff. Finally, gold contact pads about $220 \mathrm{~nm}$ thick are fabricated using sputter deposition and liftoff.

The completed wafer is diced and selected chips are mounted to alumina substrates using conductive epoxy. After wire bonding, a protective lid is glued to the substrate, and the completed sensor is mounted in an enclosure specially made to reduce transmission line effects associated with the voltage input leads [11]. A photograph of a bifilar MJTC without the lid is shown in Fig. 1.

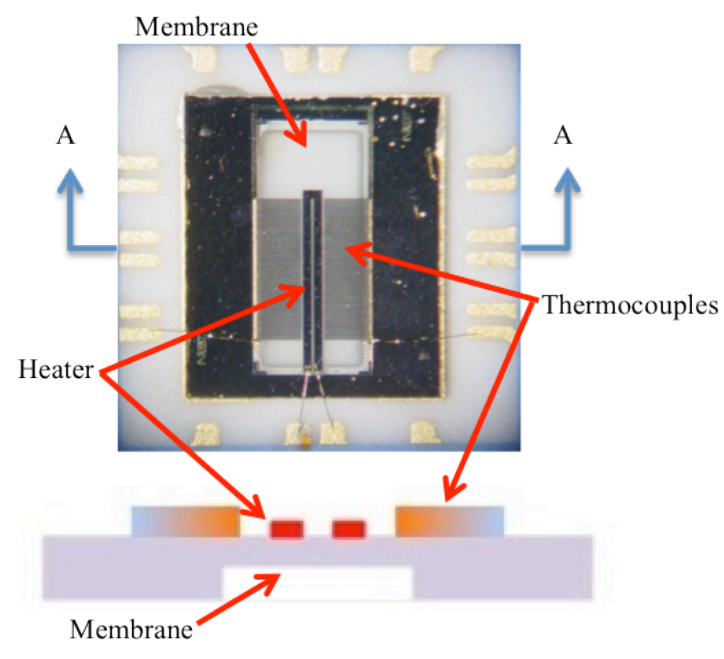

Figure 1. Photograph of bifilar chip showing the features of the design, and a cross-sectional view through A-A.

\section{RESULTS}

The completed modules are tested against the NIST primary standards for ac-dc difference at frequencies from about $100 \mathrm{~Hz}$ to $1 \mathrm{MHz}$, and then from $1 \mathrm{MHz}$ to $100 \mathrm{MHz}$ using standards for high-frequency ac-dc difference. Depending on the heater resistance, the output emf of the completed chips ranges from about $2 \mathrm{mV}$ to more than $10 \mathrm{mV}$ with $2 \mathrm{~V}$ applied.

Results are shown in Fig. 3 for several MJTCs of various designs and input resistances in the high-frequency regime from $1 \mathrm{MHz}$ to $100 \mathrm{MHz}$. The effect of heater resistance on ac-dc difference is clearly seen; for resistances of less than about $800 \Omega$ skin effect in the heater is the dominant term 
while at higher resistances the capacitive coupling of the ac signal through the fused silica begins to dominate. The uncertainties of these measurements are shown in Table 1.

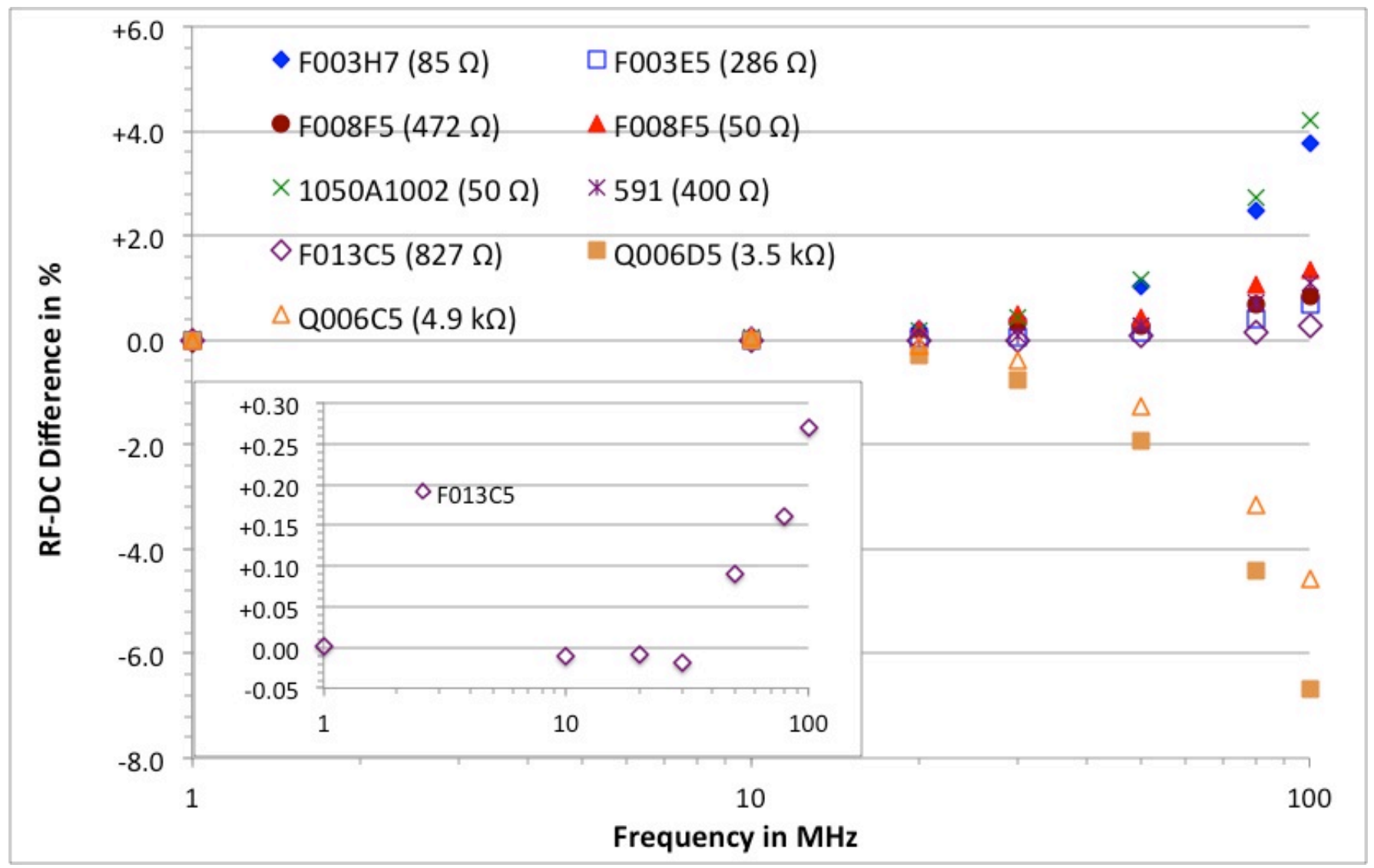

Figure 2. Results of several MJTCs compared to traditional single junction thermal converters (SJTCs). The MJTCs are denoted by either a first letter of $F$ (indicating fused silica) or Q (indicating a first-generation fused quartz MJTC). The two SJTCs (1050A1002 and 591) are representative of commerciallyavailable high-frequency thermal converters. As can be seen, the heater resistances, shown in parentheses, largely determine the RF-dc differences. Filled markers indicated coaxial MJTCs while open markers indicate bifilar MJTCs. The inset shows the RF-DC difference of F013C5 alone.

Table 1. Uncertainties, given in per cent, for Data Shown in Fig. 1.

\begin{tabular}{|c|c|c|c|c|c|c|c|}
\hline Frequency & $\mathbf{1 ~ M H z}$ & $\mathbf{1 0} \mathbf{M H z}$ & $\mathbf{2 0} \mathbf{M H z}$ & $\mathbf{3 0 ~ M H z}$ & $\mathbf{5 0} \mathbf{M H z}$ & $\mathbf{8 0} \mathbf{M H z}$ & $\mathbf{1 0 0} \mathbf{M H z}$ \\
\hline & 0.0033 & 0.010 & 0.020 & 0.030 & 0.080 & 0.100 & 0.150 \\
\hline
\end{tabular}

Although simulations of our design indicate that $700 \Omega$ input resistance should result in an RF-DC difference close to zero at $100 \mathrm{MHz}$, experimental results indicate that a resistance of $850 \Omega$ is more reasonable. It is also apparent that, for equal heater resistances, the MJTCs show smaller RF-DC differences than SJTCs at the same frequencies; this result is true not only for the SJTCs shown in Fig. 3, but a survey of high-frequency thermal converters calibrated at NIST shows that this is generally true. In fact, F013C5 is one of the best thermal converters ever tested at NIST in this frequency range. The resistances of the two crystalline quartz-based MJTCs (Q006C5 and Q006D5) preclude their use at voltages below $10 \mathrm{~V}$; however, at $1 \mathrm{MHz}$ their performance is as good as traditional thermal converters and they have been incorporated into the NIST working standards for the NIST calibration service. We anticipate that devices from wafer
F013 (including F013C5) will also be incorporated into the calibration service.

To assess the loss through the silica from capacitive coupling, F013C5 was tested as a current converter. In this measurement mode, any ac losses in the device become part of the measurement circuit (not true when measured as a voltage converter) and any ac losses can be clearly seen. The AC-DC difference of F013C5 at $100 \mathrm{kHz}$ with $5 \mathrm{~mA}$ applied to the heater was less than $25 \mu \mathrm{A} / \mathrm{A}$, indicating a minimal amount of coupling through the silica substrate. However, the AC-DC difference at $1 \mathrm{MHz}$ was about $1000 \mu \mathrm{A} / \mathrm{A}$, indicating that the silica is fairly lossy at higher frequencies. This is unlikely to affect the high-frequency error as a voltage converter. 


\section{FUtURe Plans}

Although we have demonstrated excellent performance in our $825-\Omega$ MJTCs at frequencies up to $100 \mathrm{MHz}$, our ultimate goal is to produce $50-\Omega$ MJTCs for use in impedancematching circuits. Preliminary results using $50-\Omega$ surface mount resistors to connect the two heater tracks of our bifilar design are encouraging. As can be seen in Fig. 3, converting F008F5 from a $472-\Omega$ heater to a $50-\Omega$ heater did not significantly change the RF-DC difference. We are presently determining the optimal approach to forming a $50-\Omega$ input circuit; either by fabricating such a circuit on the chip itself, or whether a resistor across the tracks on the alumina substrate is better. In addition, we wish to reduce the output resistance of the thermocouple banks and increase the output emf. We presently use $\mathrm{Cu}_{55} \mathrm{Ni}_{45}-\mathrm{Ni}_{90} \mathrm{Cr}_{10}$ thermocouples because they are easy to fabricate. In the future; however, we plan to use materials with a higher Seebeck coefficient such as $\mathrm{Bi}-\mathrm{Sb}$ or Bi-Te. We also plan to revise the mounting used with our MJTCs to reduce transmission line errors in the lead structures.

\section{CONCLUSIONS}

We have fabricated and tested new multijunction thermal converters intended for use at frequencies from $100 \mathrm{~Hz}$ to $100 \mathrm{MHz}$ at a few volts. These MJTCs will be used in the NIST calibration service for ac voltage at high frequencies, and will result in significant reductions in uncertainties. Measurements indicate that MJTCs with input resistances of about $850 \Omega$ should result in negligible frequency-dependent errors up to $100 \mathrm{MHz}$; an $827-\Omega \mathrm{MJTC}$ is one of the best thermal converters in the NIST collection of standards. We are planning new designs for MJTCs with 50- $\Omega$ input impedances that can be used in impedance-matching applications; these designs may also be useful for applications such as microwave power sensors. Future possible applications of the basic design are as pressure sensors and gas flow sensors.

\section{ACKNOWLEDGEMNTS}

This research performed in part at the NIST Center for Nanoscale Science and Technology

\section{REFERENECES}

[1] F. L. Hermach, "Thermal converters as AC-DC transfer standards for current and voltage measurements at audio frequencies," J. Res. Natl. Bur. Stand., vol. 48, no. 2, pp. 121-138, Feb. 1952.

[2] J. R. Kinard and T. - X. Cai , "Determination of AC-DC difference in the 0.1-100 MHz frequency range," IEEE Trans. Instrum. Meas., vol. 38, no. 2, pp. 360-367, Apr. 1989.

[3] F. J. Wilkins, "Theoretical analysis of the ac/dc transfer difference of the NPL multijunction thermal converter over the frequency range dc to 100 kHz,” IEEE Trans. Instrum. Meas., vol. IM-21, pp. 334-340, Nov. 1972.

[4] F. L. Hermach, J. R. Kinard, and J. R. Hastings, "Multijunction thermal converters as the NBS primary AC-DC difference standards for AC current and voltage measurements," IEEE Trans. Instrum. Meas., vol. IM-36, pp. 300-306, Jun. 1987.

[5] J. R. Kinard, D. B. Novotny, T. E. Lipe, and D. X. Huang, "Development of thin-film multijunction thermal converters at NIST," IEEE Trans. Instrum. Meas., vol. IM-46, no. 2, pp. 347-351, Apr. 1997.

[6] M. Klonz and T. Weimann, "Accurate thin-film multijunction thermal converter on a silicon chip," IEEE Trans. Instrum. Meas., vol. IM-38, no. 2, pp. 363-366, Apr. 1989.

[7] T. F. Wunsch, R. P. Manginell, O. M. Solomon, J. R. Kinard, T. E. Lipe, and K. C. Jungling, "Evaluation of coaxial single range thermal voltage converters with multijunction thin-film thermoelements," Proc. IMTC 2001, pp. 449-452, Jun. 2001.

[8] L. Scarioni, M. Klonz, D. Janik, H. Laiz, and M Kampik, "Highfrequency thin-film multijunction thermal converter on a quartz crystal chip," IEEE Trans. Instrum. Meas., vol. IM-52, no. 2, pp. 345-349, Apr. 2003.

[9] L. Scarioni, M. Klonz, T. Funck, and E. Kessler," New generation of crystal quartz thin-film multijunction thermal converters," IEEE Trans. Instrum. Meas., vol. IM-55, no. 6, pp. 2281-2285, Dec. 2006.

[10] L. Scarioni, T. E. Lipe, and J. R. Kinard, " Design and fabrication of MJTCs on quartz substrates at NIST," IEEE Trans. Instrum. Meas., vol. IM58, no. 4, pp. 868-871, Apr. 2009.

[11] G. M. Free, T. E. Lipe, J. R. Kinard, and J. E. Sims, "Characterization of RF-DC transfer difference for thermal voltage converters with built-in tees in the frequency range $1 \mathrm{MHz}$ to $1 \mathrm{GHz}$," IEEE Trans. Instrum. Meas., vol. IM56, no. 2, pp. 341-345, Apr. 2007. 